\title{
Reduction of PTEN protein and loss of epidermal growth factor receptor gene mutation in lung cancer with natural resistance to gefitinib (IRESSA)
}

\author{
Y Kokubo', A Gemma*,', R Noro', M Seike', K Kataoka', K Matsuda', T Okano', Y Minegishi', A Yoshimura', \\ M Shibuya ${ }^{i, 2}$ and S Kudoh'
}

'Fourth Department of Internal Medicine, Nippon Medical School, I-I-5 Sendagi, Bunkyo-ku, Tokyo I I 3-8602, Japan; ${ }^{2}$ Division of Respiratory Medicine, Tokyo Metropolitan Cancer and Infection Center, Komagome Hospital, 3-I 8-22 Honkomagome, Bunkyo-ku, Tokyo II 3-8677, Japan

\begin{abstract}
Gefitinib (IRESSA), an epidermal growth factor receptor (EGFR) tyrosine kinase (TK) inhibitor, has antitumour activity in the advanced non-small-cell lung cancer (NSCLC) setting. However, in chemotherapy-naiive patients with advanced NSCLC, the addition of gefitinib to standard chemotherapy regimens failed to increase survival. These results suggest the need for improved patient selection and combination rationales for targeted therapies. We have identified subpopulations of an adenocarcinoma cell line that are naturally resistant to gefitinib, and have analysed the cDNA expression profiles, genomic status of EGFR gene and the effect of gefitinib on signalling pathways in these cell lines in order to identify key mechanisms for naturally acquired resistance to gefitinib. Gefitinib-resistant subpopulations demonstrated increased Akt phosphorylation (not inhibited by gefitinib), reduced PTEN protein expression and loss of the EGFR gene mutation when compared with parental cell lines. These differences in Akt and PTEN protein expression were not evident from the cDNA array profiles. These data suggests that (I) the EGFR gene mutation may be possibly lost in some cancer cells with other additional mechanisms for activating Akt, (2) reintroduction of PTEN or pharmacological downregulation of the constitutive PI3K-Akt-pathway activity may be an attractive therapeutic strategy in cancers with gefitinib resistance.
\end{abstract}

British Journal of Cancer (2005) 92, I7II-1719. doi: I0.1038/sj.bjc.6602559 www.bjcancer.com

(c) 2005 Cancer Research UK

Keywords: gefitinib; PTEN; Akt; epidermal growth factor receptor(EGFR) gene; mutation; natural resistance

The epidermal growth factor receptor (EGFR) is a $170-\mathrm{kDa}$ protein composed of an extracellular ligand-binding domain, a short transmembrane domain and an intracellular domain with intrinsic tyrosine kinase (TK) activity (Cohen et al, 1982; Carpenter and Cohen, 1990). High expression of EGFR has been reported in various epithelial malignant tumours, including lung cancer, and has been shown to play a causal role in disease progression (Ozanne et al, 1986; Haeder et al, 1988). Epidermal growth factor receptor is, therefore, a promising molecular therapeutic target in various tumour types, including lung cancer.

Gefitinib (IRESSA) (4-(3-chloro-4-fluoroanilino)-7-methoxy-6(3-morpholinopropoxy)-quinazoline) is an orally active EGFR-TK inhibitor that inhibits EGFR signalling (Rusch et al, 1993; Salomon et al, 1995). Phase I trials of gefitinib in patients with solid tumours refractory to standard chemotherapy have shown good tolerability and evidence of antitumour activity (Ferry et al, 2000; Ranson et al, 2002). IDEAL (IRESSA Dose Evaluation in Advanced Lung cancer) 1 and 2 were randomised phase II trials in patients with non-small-cell lung cancer (NSCLC) refractory to platinum-based

*Correspondence: Dr A Gemma; E-mail: agemma@nms.ac.jp Received 5 August 2004; revised 5 January 2005; accepted 10 March 2005 chemotherapy. These trials demonstrated that gefitinib was active and generally well tolerated: response rates were 18.4 and $11.8 \%$, respectively, and the predominant toxicities were mild or moderate skin rash and diarrhoea (Fukuoka et al, 2003; Kris et al, 2003). The INTACT (IRESSA NSCLC Trial Assessing Combination Treatment) 1 and 2 phase III trials compared first-line chemotherapy with and without gefitinib in patients with advanced NSCLC and demonstrated similar survival outcomes in both treatment arms (Giaccone et al, 2004; Herbst et al, 2004). These data indicate that improved patient selection and combination strategies are required for optimal utility of this targeted therapy.

Gefitinib exerts antitumour activity through inhibition of EGFRTK, but its antitumour activity is not significantly correlated with tumour cell EGFR expression (Bailey et al, 2003). Recently, differences in the frequency of activating mutations in the EGFR gene between gefitinib responders and nonresponders were reported and these EGFR mutations seem to be predictive markers for sensitivity to gefitinib (Lynch et al, 2004; Paez et al, 2004). We examined sensitivity to gefitinib in NSCLC cell lines using the MTT (3-(4,5-dimethylthiazol-2-yl)-2,5-tetrazolium bromide) cell proliferation assay and identified a parent adenocarcinoma cell line, PC9, that was sensitive to gefitinib and two subpopulations, PC9/f9 and PC9/f14, that were resistant. These subpopulations of PC9 were established by artificial metastasis methods and resistance to 
gefitinib was therefore acquired naturally, without exposure to gefitinib. In order to identify additional key molecules involved in gefitinib resistance, we analysed expression profiles using cDNA array and genomic status of the EGFR gene in the parent cell line and subpopulations, and examined the effect of gefitinib on the downstream mediators of EGF-mediated signalling PI3K-Akt and Ras/MEK/Erk pathways (Olayioye et al, 2000).

\section{MATERIALS AND METHODS}

\section{Cell lines}

Using the MTT assay, we analysed the growth-inhibitory effect of gefitinib on nine NSCLC cell lines: A549, PC3, PC7, PC9, PC9/f9, PC9/f14 and PC14 adenocarcinoma cell lines, Lu65 large-cell carcinoma cell line and LK-2 squamous-cell carcinoma cell line. PC9/f9 (Takenaka et al, 2000) and PC9/f14 (Gemma et al, 2001) are highly metastatic sublines of PC9 established at Nippon Medical School using artificial metastasis methods. In an attempt to elucidate potential mechanisms of resistance to gefitinib, we evaluated cDNA expression profiles and their relationship to gefitinib resistance. We also specifically examined the effect of gefitinib on the PI3K-Akt and Ras/MEK/Erk pathways in PC9, PC9/f9 and PC9/f14 cells.

\section{Drugs and growth-inhibition assay}

Gefitinib was provided by AstraZeneca, Macclesfield, UK and dissolved in dimethyl sulphoxide (DMSO) for in vitro studies. We used the colourimetric MTT assay (tetrazolium dye assay) to examine the activity of gefitinib on NSCLC cell lines (Mosmann, 1983). Cell suspensions $\left(200 \mu \mathrm{l} 1 \times 10^{5} \mathrm{cells} \mathrm{ml}^{-1}\right)$ were seeded into the wells of a 96 -well microtitre plate and $10 \mu \mathrm{l}$ of drug solution (various concentrations) was added. After incubation for $72 \mathrm{~h}$ at $37^{\circ} \mathrm{C}, 20 \mu \mathrm{l}$ of MTT solution $\left(5 \mathrm{mg} \mathrm{ml}^{-1}\right.$ in phosphate-buffered saline) was added to each well and incubated for a further $4 \mathrm{~h}$ at $37^{\circ} \mathrm{C}$. After centrifugation at 1500 r.p.m. for $5 \mathrm{~min}$, the medium was aspirated from each well and $200 \mu \mathrm{l}$ of DMSO was added to dissolve the formazan. The $\mathrm{IC}_{50}$ value was defined as the concentration needed for a $50 \%$ reduction in absorbance $(560 \mathrm{~nm})$ based on survival curves.

\section{RNA isolation, cDNA array hybridisation and analysis of hybridisation signals}

Total RNA was isolated from each cell line using standard protocols described previously (Gemma et al, 1996, 1998). Messenger RNA was then purified from total RNA by incubation with oligo-dT-magnetic beads (Toyobo Co., Osaka, Japan). The ElectorGene Array System (GeneticLab Co. Ltd, Sapporo, Japan) was used for filter-based cDNA array analysis, as previously reported (Gemma et al, 2001). In this analysis, 1300 species of human DNA fragments, including cancer-related and drugresistance-associated genes, as well as housekeeping and nonmammalian genes as negative controls, are spotted in duplicate on a filter. The probes were prepared by reverse transcription (Reverse Transcriptase, ReverTraAce (Toyobo Co., Osaka, Japan)), with a random 9 mer (Toyobo Co., Osaka, Japan) and $5 \mathrm{mg}$ of poly A RNA. The probes were labelled with biotin by incorporation of biotin-16-deoxyuracil triphosphate during the synthesis of cDNA. The filters were preincubated in $20 \mathrm{ml}$ of PerfectHyb (Toyobo Co., Osaka, Japan) at $68^{\circ} \mathrm{C}$ for $30 \mathrm{~min}$. The biotin-labelled probes were denatured and added to the prehybridisation solution and the filters were incubated overnight at $68^{\circ} \mathrm{C}$ in the hybridisation mixture. After washing, specific signals on the filters were detected by the Imaging High-Chemilumi-Detection kit (Toyobo Co., Osaka, Japan). CDP-Star substrate (Tropix, Bedford, MA, USA) was used as the chemiluminescence substrate, and a chemilumi- nescence image of the filter was acquired by Fluor-S (Bio-Rad, Hercules, CA, USA). Gene-expression images were quantified by measuring the intensity of the signals using Imagene (BioDiscovery, Los Angeles, CA, USA) and filter signal intensity was analysed by the ElectorGene Finding System (GeneticLab Co. Ltd, Sapporo, Japan). The background threshold was set at a level three-fold higher than the negative control. Signal intensities were normalised by comparison with the expression of housekeeping genes, GAPDH (glyceraldehyde-3-phosphate dehydrogenase) and betaactin. A three-fold difference in gene expression among the subpopulations and the parent cell line was considered to be significant, on the basis of the company's recommendation (Toyobo Co., Osaka, Japan).

\section{Effect of gefitinib on PI3K-Akt and Ras/MEK/Erk pathways in PC9, PC9/f9 and PC9/f14 cells}

Exposure to gefitinib PC9, PC9/f9 and PC9/f14 cells were serumstarved and treated with various concentrations of gefitinib $(0,5$, 50,500 and $5000 \mathrm{ng} \mathrm{ml}^{-1}$ ) for $2 \mathrm{~h}$ before exposure to $10 \mathrm{ng} \mathrm{ml}^{-1}$ EGF (BA-53) (Santa Cruz Biotechnology, Santa Cruz, CA, USA) for $5 \mathrm{~min}$.

Western blot analysis Lysis buffer containing 1\% Triton X and $1 \%$ NP40 was added to the cells before sonication in a POLYTRON homogenizer (KINEMATICA, Littau-Lucerne, Switzerland). The lysates were cleared by centrifugation at 14000 r.p.m. for $20 \mathrm{~min}$, and then $10 \mu \mathrm{l}$ of lysate containing $10 \mu \mathrm{g}$ of protein were separated by SDS-polyacrylamide gel electrophoresis (PAGE). After PAGE, the proteins were transferred to nitrocellulose membranes and blotted with the following primary antibodies: PTEN A2B1 (Santa Cruz Biotechnology, Santa Cruz, CA, USA), and Akt, phospho-Akt (Ser473), p38 MAP kinase and phospho-p38 MAP kinase (Thr180/Tyr182) (all Cell Signaling Technology, Beverly, MA, USA). The membranes were then incubated with peroxidaseconjugated secondary antibodies and protein was detected with the ECL Western blotting detection reagents (Amersham, Buckinghamshire, UK) (Naishiro et al, 2001) and film-processor FPM100 film (Fuji Photo Film). These images were quantified by measuring the intensity of the signals using NIH Image (ImageJ1.32j).

\section{Genomic DNA analysis of the PTEN gene by polymerase chain reaction}

From each genomic DNA sample, all exons of the PTEN gene were amplified separately with the polymerase chain reaction (PCR) primers previously described (Hosoya et al, 1999) using the Gene Amp XL PCR kit (Perkin Elmer/Roche, Branchburg, NJ, USA). Polymerase chain reaction conditions for genomic DNA analysis were as follows: 40 cycles at $94^{\circ} \mathrm{C}$ for $40 \mathrm{~s}$, at $60^{\circ} \mathrm{C}$ for $30 \mathrm{~s}$ and at $68^{\circ} \mathrm{C}$ for $90 \mathrm{~s}$, followed by $68^{\circ} \mathrm{C}$ for $8 \mathrm{~min}$. Each reaction mixture contained $1 \times \mathrm{XL}$ buffer, $200 \mu \mathrm{M}$ deoxynucleotide triphosphate, $1100 \mu \mathrm{M} \mathrm{Mg}(\mathrm{OAc}) 2,0.5 \mathrm{U}$ rTth DNA polymerase XL, $0.3 \mathrm{~mm}$ of each primer (one of each pair) (Hosoya et al, 1999) and $25 \mathrm{ng}$ of genomic DNA. Polymerase chain reaction products were loaded on $1.2 \%$ agarose gels. After electrophoresis, the gels were analysed.

\section{Mutation analysis of the EGFR gene}

Polymerase chain reaction-single strand conformation polymorphism (PCR-SSCP) analysis was performed as previously described (Gemma A, et al, 1996, 1998). Each of the three exons $(18,19$ and 21$)$ of the EGFR gene was amplified separately using reported PCR primers (Lynch et al, 2004). Polymerase chain reaction was performed using the Gene AMP XL PCR kit (PerkinElmer Corp./Roche, Branchburg, NJ, USA) as described above. The 
PCR reaction mixture contained XL buffer containing $1100 \mu \mathrm{M}$ $\mathrm{Mg}(\mathrm{OAc})_{2}, 200 \mu \mathrm{M}$ deoxynucleotide triphosphate, $0.1 \mathrm{~mm}$ of each primer labelled with 5-IAF (Amersham Pharmacia Biotech, Uppsala, Sweden ), $0.5 \mathrm{U}$ of rTth DNA polymerase and $25 \mathrm{ng}$ of genomic DNA. The 5-IAF-labelled PCR products were denatured, cooled on ice, and loaded on neutral $6 \%$ polyacrylamide gels with or without $5 \%\left(\mathrm{vol} \mathrm{vol}^{-1}\right)$ glycerol. Following electrophoresis, the gels were analysed using the FluorImager 595 (Amersham Pharmacia Biotech, Uppsala, Sweden). DNA sequence analysis was performed as previously described (Gemma A, et al, 1996, 1998). Aberrant bands were cut from the gel and further amplified by PCR using sequencing primers with the M13 sequence (TGTAAAACGACGGCCAGT) added to the appropriate PCR primers. Sequencing reaction was performed, and the products were purified and sequenced using a fluorescent automated sequencer (Perkin-Elmer Corp./Applied Biosystem, Inc., Foster City CA, USA).

Multicolour fluorescent in situ hybridisation (FISH) analyses of metaphase preparations from cancer cell line subpopulation

Multicolour-FISH on metaphase preparations was performed using Spectra Vysion probes according to the instructions of the manufacturer (Vysis, Downers Grove, IL, USA). Images were visualised by an epifluorescence microscope (Zeiss, Oberhochen, Germany) and analysed using an Applied Imaging CytoVision Work station (Newcastle, UK, USA). A total of 20 metaphase cells were analysed in each subpopulation.

\section{RESULTS}

\section{Effect of gefitinib on cell growth in vitro}

The $\mathrm{IC}_{50}$ values of gefitinib on nine NSCLC cell lines, as determined by the MTT assay, are summarised in Table 1. In accordance with the minimal steady-state concentration reported in the clinical trial $\left(264 \mathrm{ng} \mathrm{ml}^{-1} ; 0.59 \mu \mathrm{M}\right)$, PC9 and A549 seemed to be sensitive to gefitinib. Interestingly, two subpopulations of the PC9 cell line, PC9/f9 and PC9/f14, showed resistance to gefitinib even though the parent cell line was sensitive. A highly metastatic human lung adenocarcinoma cell line, PC9/f9, was established in an experimental metastasis model by repeated inoculation of PC9

Table I In vitro growth-inhibitory activity of gefitinib on NSCLC cell lines in the MTT assay

\begin{tabular}{lll}
\hline Cell line & Cell type & IC $_{\mathbf{5 0}}(\boldsymbol{\mu} \mathbf{M})$ \\
\hline PC9 & Adenocarcinoma & $2.0 \times 10^{-3}$ \\
PC9/f9 & Highly metastatic subpopulation of PC9 & $>20$ \\
PC9/fI4 & Highly metastatic subpopulation of PC9 & 19 \\
A549 & Adenocarcinoma & $1.8 \times 10^{-2}$ \\
PC7 & Adenocarcinoma & $>20$ \\
PCI4 & Adenocarcinoma & 8.0 \\
PC3 & Adenocarcinoma & $>20$ \\
LU65 & Large-cell carcinoma & 13 \\
LK-2 & Squamous-cell carcinoma & 20 \\
\hline
\end{tabular}
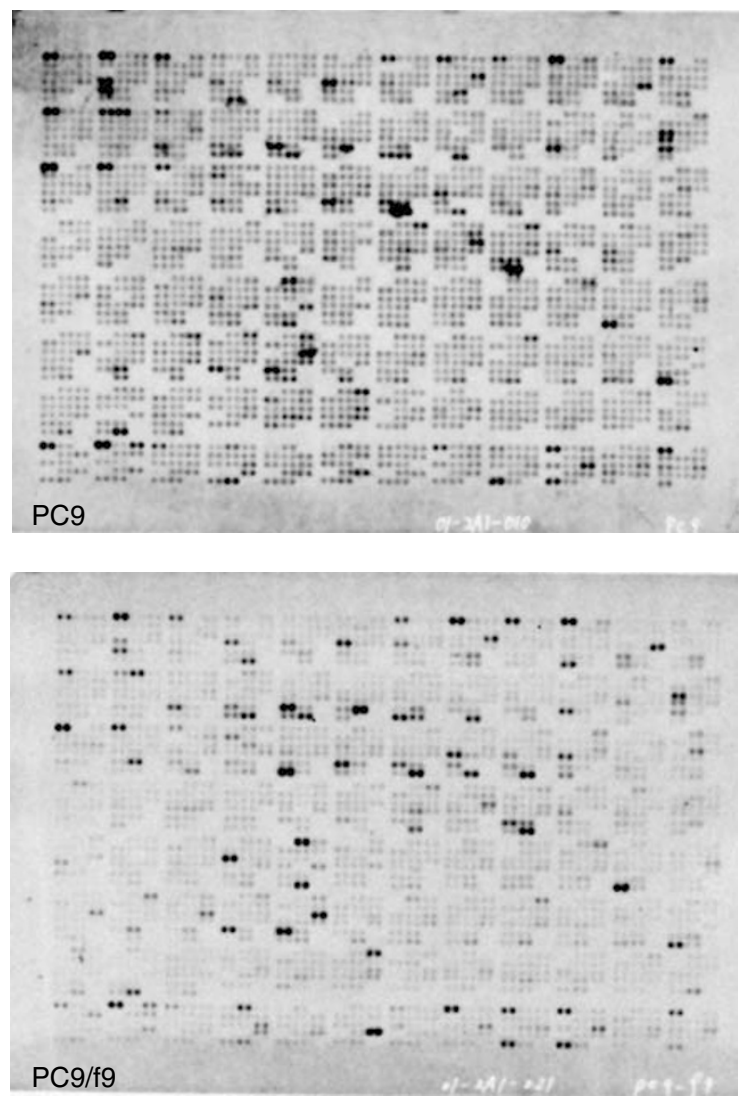
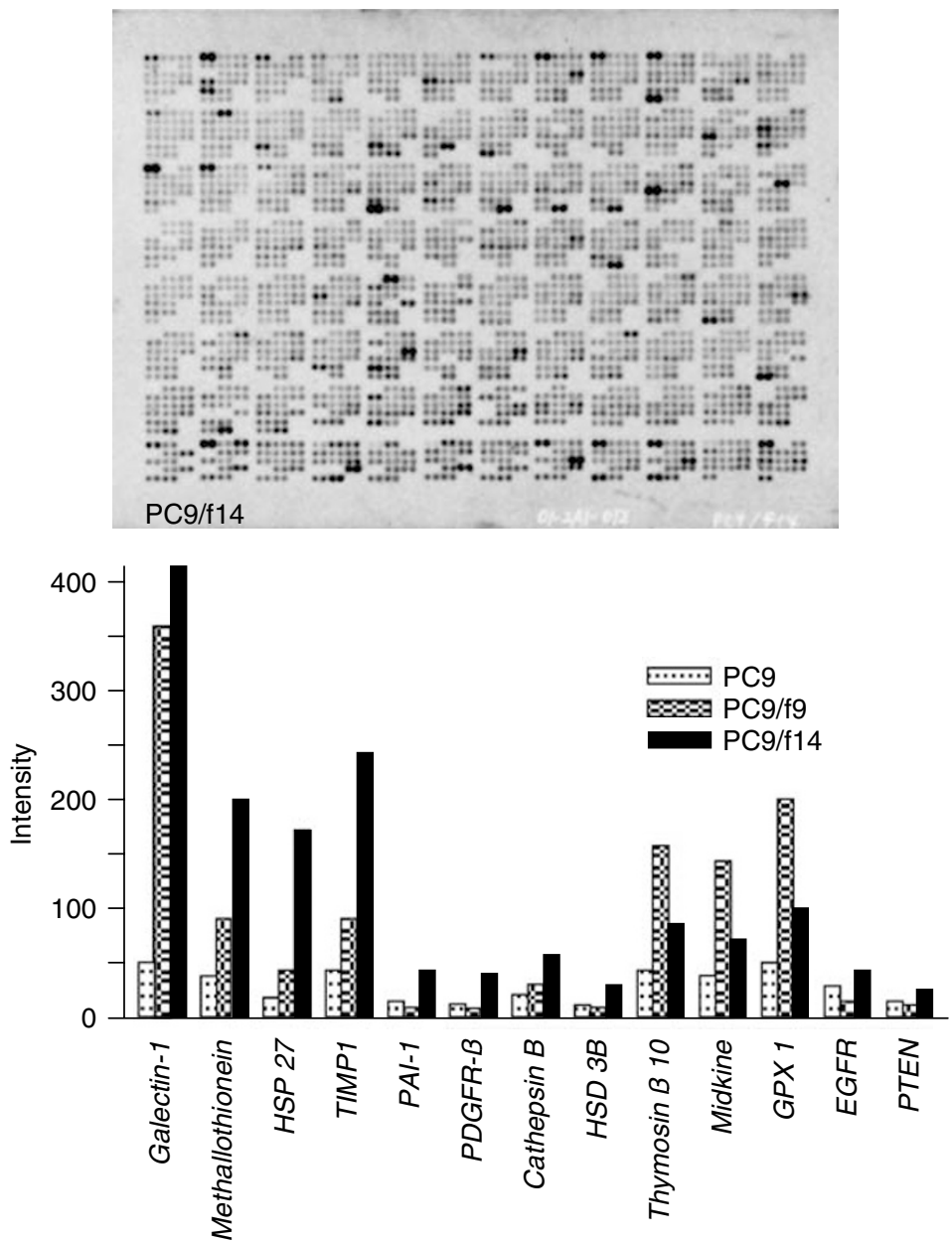

Figure I Expression profiles of the sensitive cell line PC9 and resistant subpopulations PC9/f9 and PC9/fl4 using cDNA array. 
cells in nude mice and subsequent culture of the tumour cells harvested from pulmonary metastatic foci (Takenaka et al, 2000). PC9/f14 was established by five additional inoculations (Gemma et al, 2001). In the matrigel invasion assay, the PC9/f9 and PC9/f14 cells showed higher invasive activity than the parent PC9 cells (data not shown). The resistance to gefitinib in PC9/f9 and PC9/f14 cells was therefore acquired naturally in the absence of exposure to gefitinib.

\section{cDNA array analysis in PC9, PC9/f9 and PC9/f14 cells}

In order to identify potential key molecules for natural resistance to gefitinib, we analysed the expression profiles of the PC9, PC9/f9 and PC9/f14 cell lines using cDNA array, and examined the effect of gefitinib on the EGF downstream mediators PI3K-Akt and Ras/MEK/Erk. Significant enhancement of four and eight genes was identified in the PC9/f9 and PC9/f14 cell lines, respectively, compared with the parent cell line. Only Galectin-1 was overexpressed in both of the resistant cell lines and lactate dehydrogenase $A$ was downregulated. There were no significant differences in EGFR expression, nor were Ras, $P T E N, P I 3 K, A k t$, Raf or ERK1/2 differentially expressed (Figure 1).

\section{Phosphorylation of Akt in PC9, PC9/f9 and PC9/f14 cells}

We examined expression and phosphorylation (Ser473) of Akt in PC9, PC9/f9 and PC9/f14 cells using Western blot analysis. There were no significant differences in Akt expression between the parent cell line and subpopulations. However, PC9/f9 and PC9/f14 cells demonstrated increased Akt phosphorylation compared with PC9 cells (Figure 2).

\section{Expression of PTEN in PC9, PC9/f9 and PC9/f14 cells}

We also examined expression of PTEN, a phosphatase that can dephosphorylyse position D3 of phosphatidylinositol-3,4,5 triphosphatase and which is a major negative regulator of the PI3 kinase/ Akt signalling pathway (Cantley and Neel, 1999; Simpson and Parsons, 2001). PC9 demonstrated moderate expression of PTEN and there was minimal or absent expression of PTEN in PC9/f9 and PC9/f14 cells (Figure 3). Frequent homozygous deletion of the PTEN gene has been reported in lung cancer (Kohno et al, 1998; Ali et al, 1999; Vivanco and Sawyers, 2002), so we performed screening of genomic DNA analysis by PCR. We detected no homozygous deletions of the PTEN gene in any of the three subpopulations of the cell line examined (Figure 4).

\section{Expression and phosphorylation state of p38 MAP kinase in PC9, PC9/f9 and PC9/f14 cells}

We then examined the expression and phosphorylation state of p38 MAP kinase in PC9, PC9/f9 and PC9/f14 cells. p38 MAP kinase is activated by a variety of cellular stresses including osmotic shock, inflammatory cytokines, ultraviolet light, and growth factors. Phospho-p38 MAP kinase antibody detects p38 MAP kinase only when activated by dual phosphorylation at Thr180 and Tyr182. PC9 demonstrated activated p38 but only minimally activated p38 was observed in PC9/f9 and PC9/f14 cells (Figure 5).

\section{Mutation of EGFR gene in these cell lines}

Polymerase chain reaction-SSCP analysis was performed on these three lung cancer cell line subpopulations. The reported mutation in the EGFR gene was detected in parent cell line, PC9 (Arao T, et al, 2004), but no mutation were detected in PC9/f9 and PC9/f14
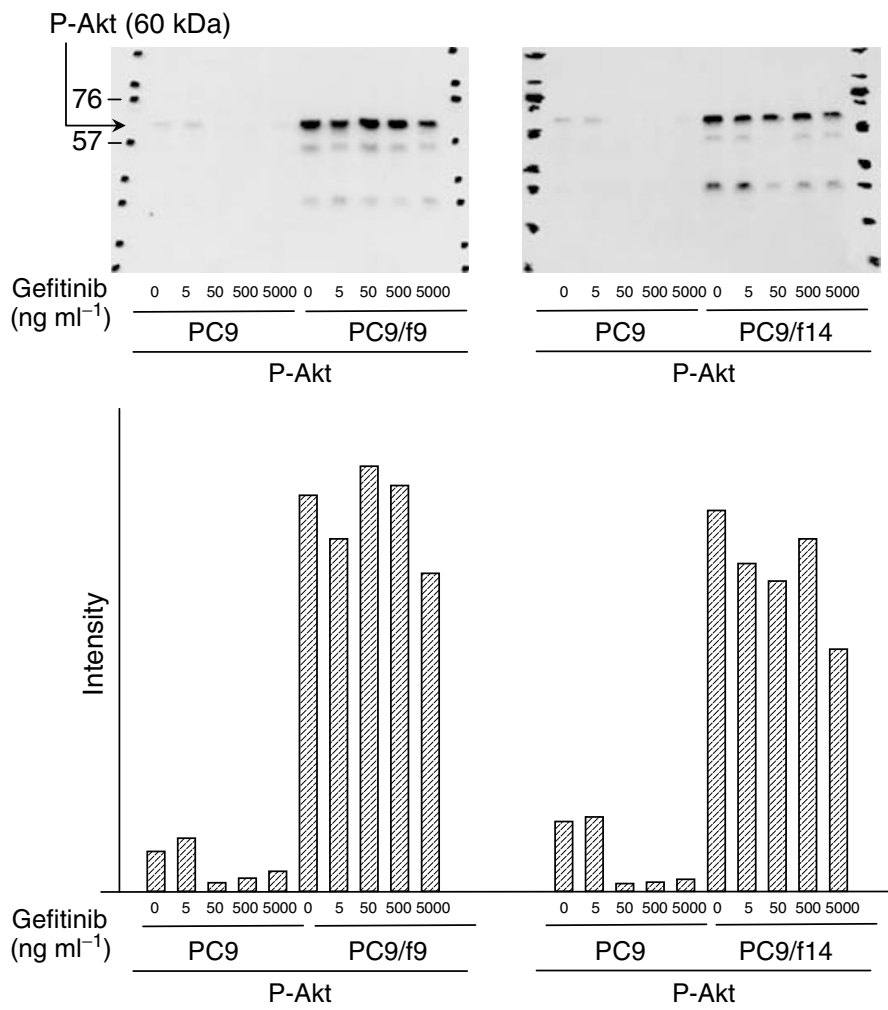

Akt $(60 \mathrm{kDa})$
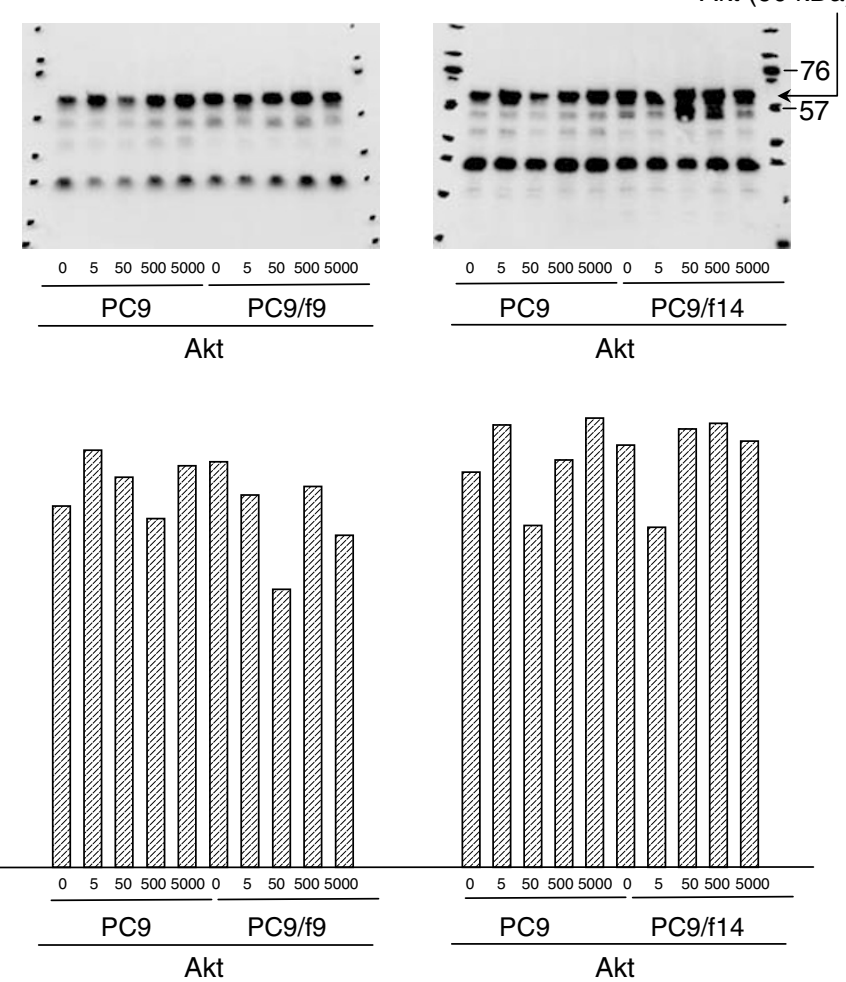

Figure 2 Expression and phosphorylation state of Akt in the sensitive cell line PC9 and resistant subpopulations PC9/f9 and PC9/f।4, and dose-dependent effect of gefitinib. 


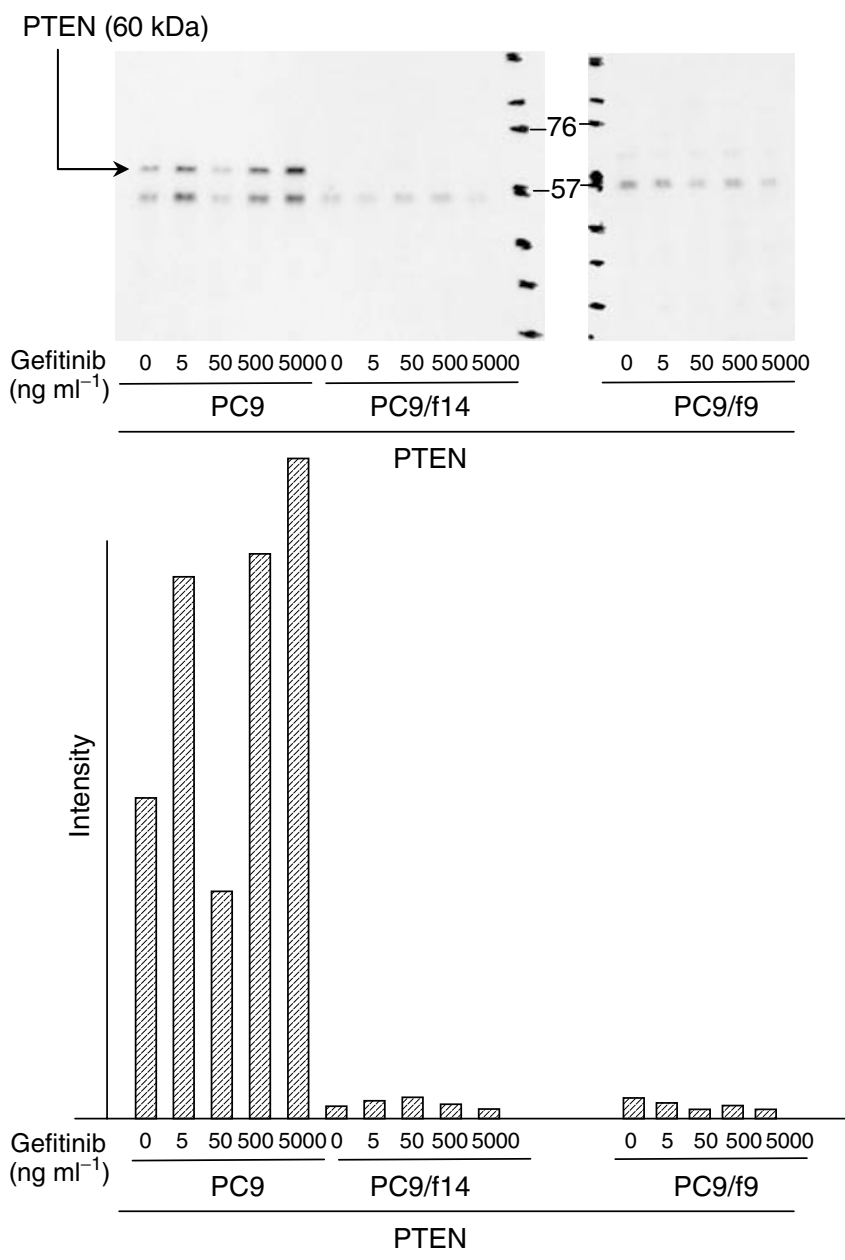

Figure 3 Expression of PTEN in the sensitive cell line PC9 and resistant subpopulations PC9/f9 and PC9/f/4, and dose-dependent effect of gefitinib.

(Figure 6). We performed karyotype analyses using multicolour FISH analysis to confirm that these subpopulations have same origin. The multicolour FISH analyses demonstrated that these subpopulations had similar chromosome numbers and chromosomal rearrangements (at least, eight common rearrangements) (Figure 7). These results showed that these subpopulations with naturally acquired resistance to gefitinib lost the EGFR gene mutation.

\section{Effect of gefitinib on phosphorylation of Akt and p38 MAP kinase and expression of PTEN}

Using Western blot analysis, we also examined the effect of gefitinib on PTEN expression, and expression and phosphorylation of Akt and p38 MAP kinase in PC9, PC9/f9 and PC9/f14 cells. While gefitinib had no influence on Akt phosphorylation in PC9/f9 and PC9/f14 cells, it inhibited Akt phosphorylation in PC9 cells, with complete inhibition of Akt phosphorylation observed at gefitinib concentrations $\geqslant 0.1 \mu \mathrm{M}\left(44.7 \mathrm{ng} \mathrm{ml}^{-1}\right)$. Notably, this concentration is substantially lower than that reported as the minimal steady-state concentration in clinical trials (Ranson et al, 2002). In PC9 cells, gefitinib was associated with increased PTEN expression, but there was absent or only minimal expression of PTEN in PC9/f9 and PC9/f14 cells and gefitinib did not influence expression. Gefitinib did not influence the expression or phosphorylation state of p38 MAP kinase (Figures 2, 3 and 5).

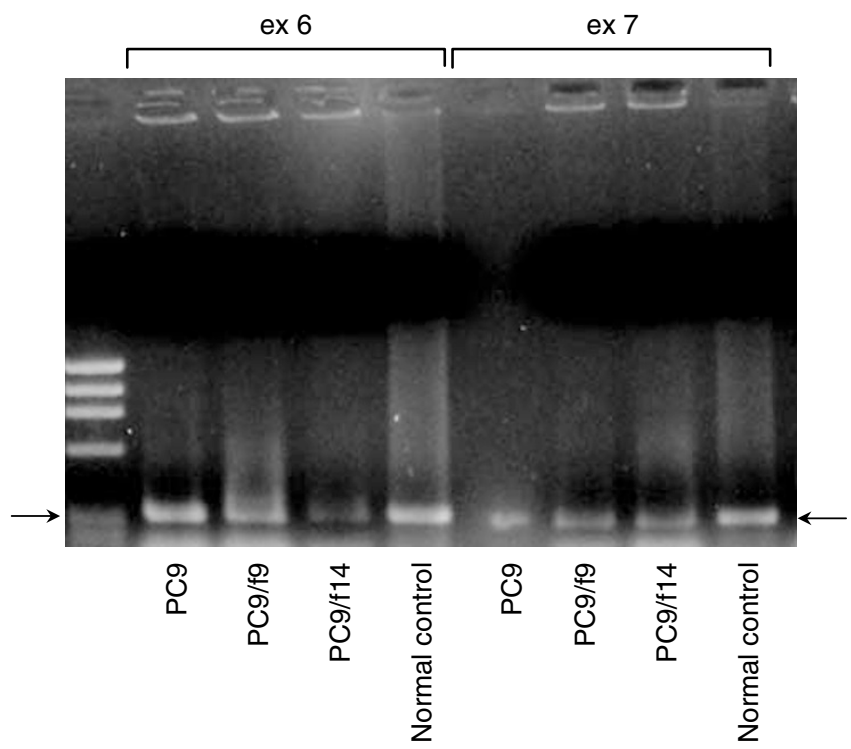

Figure 4 Genomic DNA analysis of the PTEN gene in sensitive cell line PC9 and resistant subpopulations PC9/f9 and PC9/fI4.

\section{DISCUSSION}

Gefitinib exerts antitumour activity through inhibition of EGFRTK (Rusch et al, 1993; Salomon et al, 1995), but its antitumour activity cannot be predicted by EGFR expression in tumours (Bailey et al, 2003). Recent reports showing differences in the frequency of activating mutations in the EGFR gene between gefitinib responders and nonresponders suggest that these EGFR mutations are predictive markers for sensitivity to gefitinib (Lynch et al, 2004; Paez et al, 2004). However, there are also sensitive tumors to gefitinib without the EGFR gene mutation. We examined the sensitivity of various NSCLC cell lines to gefitinib using the MTT assay and attempted to identify potential key molecules involved in gefitinib resistance. We identified PC9, a parent adenocarcinoma cell line sensitive to gefitinib, and two resistant subpopulations, $\mathrm{PC} / \mathrm{f} 9$ and PC9/f14. As the artificial metastasis method was used for subpopulation generation, PC9/f9 and PC9/ f14 had highly metastatic potential and natural resistance to gefitinib.

We analysed the expression profiles using cDNA array, genomic status of the EGFR gene, and examined the effect of gefitinib on the downstream mediators of EGF-mediated signalling PI3K-Akt and Ras/MEK/Erk (Olayioye et al, 2000) pathways in these subpopulations. Both resistant subpopulations demonstrated increased activation of Akt, reduced expression of PTEN and loss of the EGFR gene mutation, compared with the parent cell line. Gefitinib inhibited Akt phosphorylation in the gefitinib-sensitive parent cell line but not in the resistant subpopulations PC9/f9 and PC9/f14.

She et al (2003) reported that the MDA468 breast cancer cell line, which lacks PTEN function, was resistant to gefitinib. Reconstitution of PTEN function in MDA468 cells through tetinducible expression restored gefitinib sensitivity and re-established EGFR-stimulated Akt signalling. Bianco et al (2003) also reported that loss of PTEN in MDA468 counteracted the antitumour action of EGFR-TK inhibitors and that restoration of PTEN by retroviral infection was associated with gefitinibmediated inhibition of Akt phosphorylation, and increased apoptosis and cell-cycle delay.

In accordance with these data, our results demonstrated loss of PTEN protein and overactivation of Akt in NSCLC subpopulations with highly metastatic potential and natural resistance to gefitinib, 

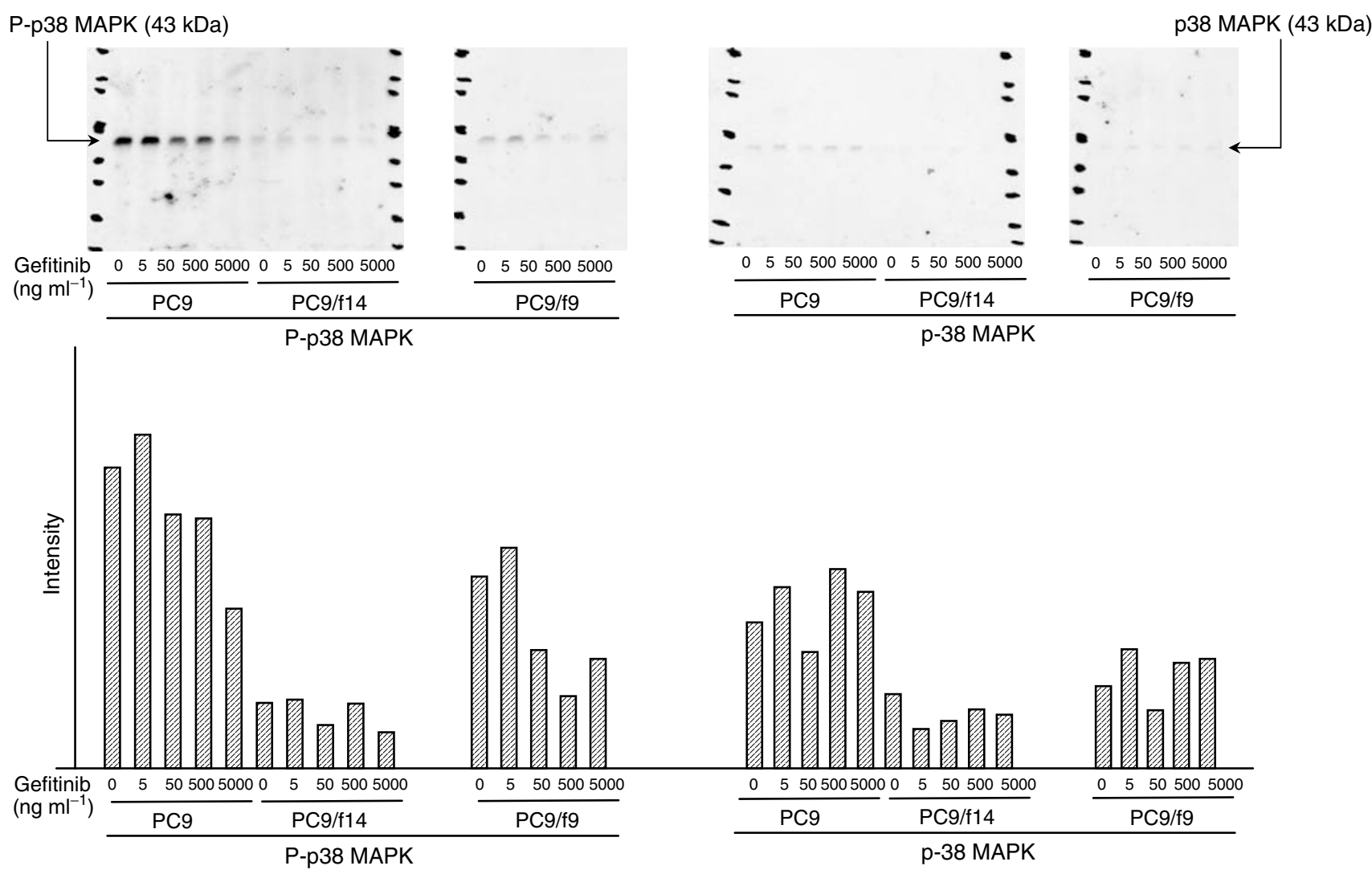

Figure 5 Expression and phosphorylation state of p38 MAP kinase in the sensitive cell line PC9 and resistant subpopulations PC9/f9 and PC9/fI4, and dose-dependent effect of gefitinib.

and indicated that PTEN protein level and Akt phosphorylation state may be additional key predictors of de novo resistance to gefitinib. Reintroduction of PTEN or pharmacological downregulation of constitutive PI3K-Akt-pathway activity might potentially sensitise lung carcinomas to gefitinib, although further preclinical studies are required.

There are many reports of Akt-promoted tumour invasion and metastasis. Park et al (2001) showed that Akt1 induced extracellular matrix invasion and matrix metalloproteinase (MMP)-2 activity in mouse mammary epithelial cells. Kim et al (2001) also demonstrated that Akt/protein kinase-B promoted cancer cell invasion via increased motility and MMP production. Overexpression of Akt2 was also reported to lead to upregulation of beta-1 integrins and increased invasion and metastasis of human breast and ovarian cancer cells by Arboleda et al (2003). We established highly metastatic human lung adenocarcinoma cell subpopulations, PC9/f9 and PC9/f14, in an experimental metastasis model by repeated inoculation of PC9 cells in nude mice and subsequent culture of the tumour cells that were harvested from pulmonary metastatic foci. The PC9/f9 and PC9/f14 cells showed higher invasive activity in the matrigel invasion assay than the parent PC9 cells (data not shown). Our data indicated that loss of PTEN and overactivation of Akt during the repeated process of artificial metastasis were associated with increased invasive activity and may have contributed to natural resistance to gefitinib. Loss of the EGFR gene mutation in PC9/f9 and PC9/f14 indicated that constitutive Akt phosphorylation by EGFR gene mutation does not seem to be necessary in some cancer cells with other additional mechanisms of activating Akt.

In the expression profile analysis using cDNA array, we could identify several molecules that were significantly up- or downregulated in the gefitinib-resistant subpopulations compared with the parent cell line. However, while the resistant subpopulations demonstrated increased activation of Akt and reduced expression of PTEN in Western blot analysis, we could not identify significant differences in PTEN and $A k t$ using cDNA array. Furthermore, Western blot analysis failed to demonstrate a difference in Akt gene expression between parent and resistant subpopulations. The failure to demonstrate homozygous deletions of the PTEN gene in these subpopulations and differences in PTEN mRNA levels between the sensitive and resistant cell subpopulations indicates that the reduced PTEN protein expression in these gefitinib-resistant cells may be the result of post-translational regulation or partial genomic alterations. Our data indicate that, at this time, gene expression profile analysis may not be sufficient for the identification of potential key molecules in gefitinib resistance, and protein expression and evaluation of phosphorylation status may be more informative. The reduced phosphorylation of p38 observed in PC9/f9 and PC9/f14 cells in our study indicates that gefitinib resistance may be affected through a negative feedback mechanism.

Homozygous deletion of the PTEN gene has been reported in lung cancer (Kohno et al, 1998; Ali et al, 1999; Vivanco and Sawyers, 2002). The results of our study indicate that PTEN protein expression and Akt phosphorylation may be candidate markers of gefitinib sensitivity; conversely, lack of PTEN expression and Akt phosphorylation may be candidate markers of gefitinib resistance. Those tumours with activating mutations in the EGFR gene but which lack PTEN may be resistant to gefitinib, as PTEN is located downstream of the EGFR. Since Akt phosphorylation is influenced by activating mutations in the EGFR gene and loss of PTEN function, Akt phosphorylation alone could not be a secondary 
A

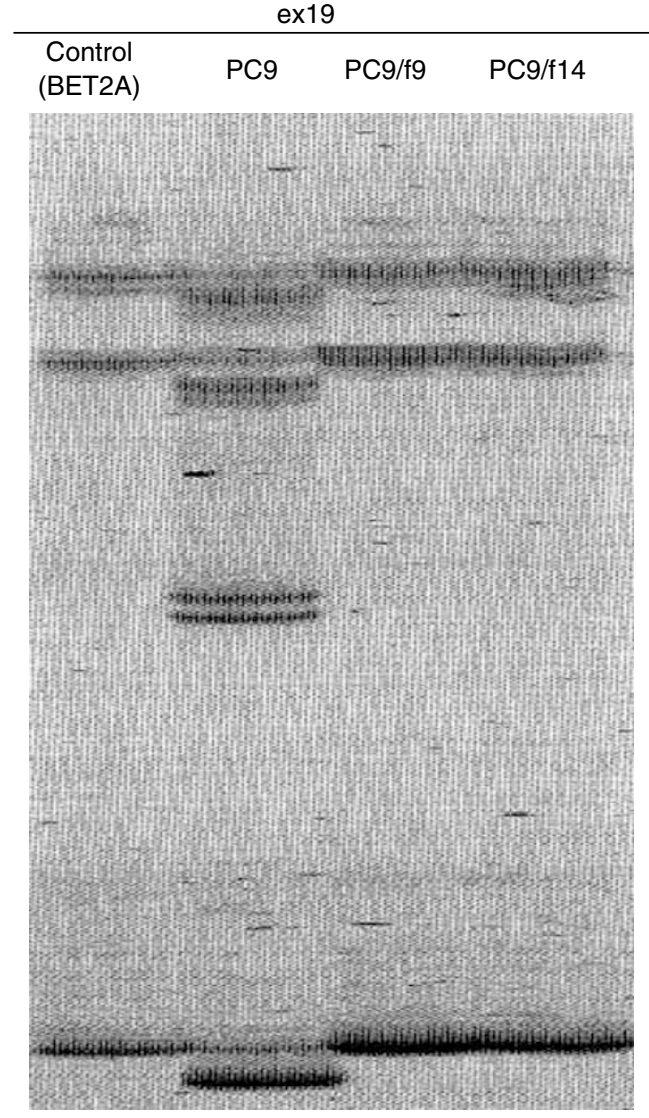
B Exon19-PC9 TA A A (DelE746-A750)

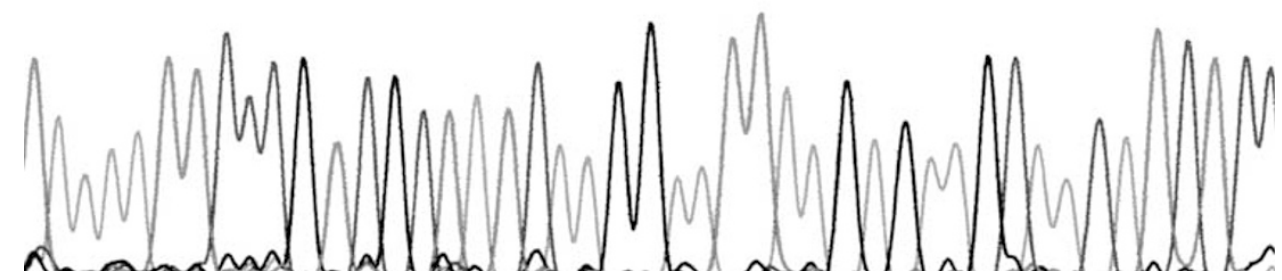

Figure 6 (A) Polymerase chain reaction-SSCP analysis of the EGFR gene in PC9, PC9/f9 and PC9/f।4. Aberrant bands were shown only in PC9. (B) Sequence of aberrant and normal bands. These sequence analyses showed deletion of the EGFR gene in PC9.

marker of these EGFR mutations. More extensive clinical study using biopsy samples may be useful for further evaluation of PTEN protein expression as a marker for gefitinib sensitivity.
Finally, the EGFR gene mutation may be lost in some cancer cells with other additional mechanisms of activating Akt. This alteration might be a novel mechanism and/or marker for acquired 

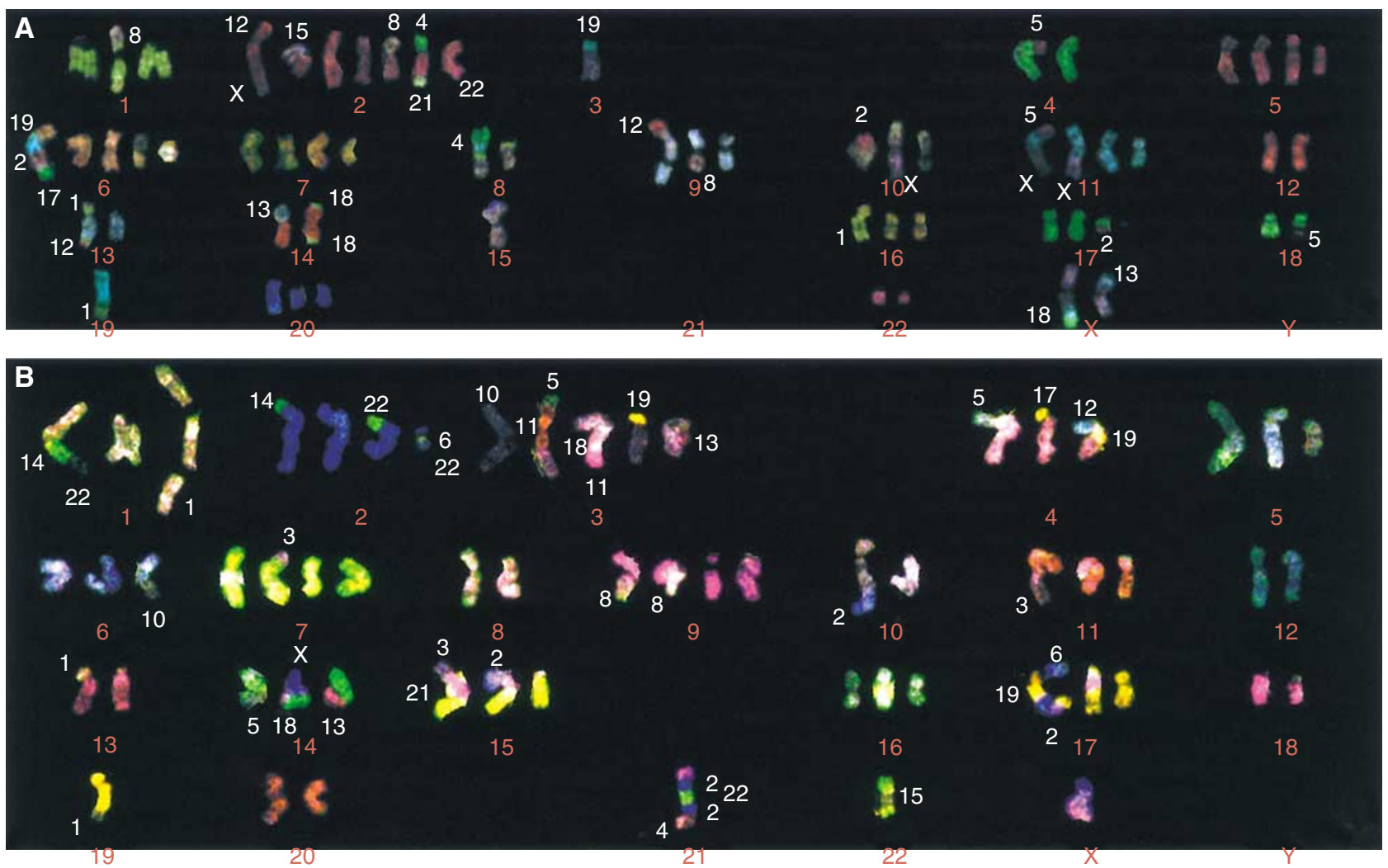

Figure 7 Multicolour FISH analyses of PC9 (A) and PC9/fI4 (B). Chromosome numbers of PC9 and PC9/fI4 are 6I and 60, respectively. Common aberrant chromosomes are eight.

resistance to gefitinib. Reintroduction of PTEN or pharmacological downregulation of the constitutive PI3K-Akt-pathway activity may be an attractive therapeutic strategy in cancers without the EGFR gene mutation. The existence of these cell line subpopulations will facilitate investigation of EGF-mediated signalling PI3KAkt in human cancers.

\section{REFERENCES}

Ali IU, Schriml LM, Dean M (1999) Mutational spectra of PTEN/MMAC1 gene: a tumor suppressor with lipid phosphatase activity. J Natl Cancer Inst 91: $1922-1932$

Arao T, Fukumoto H, Takeda M, Tamura T, Saijo N, Nishio K (2004) Small in-frame deletion in the epidermal growth factor receptor as a target for ZD6474. Cancer Res 64: 9101 -9104

Arboleda MJ, Lyons JF, Kabbinavar FF, Bray MR, Snow BE, Ayala R, Danino M, Karlan BY, Slamon DJ (2003) Overexpression of AKT2/ protein kinase $\mathrm{B} \beta$ leads to up-regulation of $\beta 1$ integrins, increased invasion, and metastasis of human breast and ovarian cancer cells. Cancer Res 63: 196-206

Bailey LR, Kris M, Wolf M, Kay A, Averbuch S, Askaa J, Janas M, Schmidt K, Fukuoka M (2003) Tumor EGFR membrane staining is not clinically relevant for predicting response in patients receiving gefitinib ('Iressa', ZD1839) monotherapy for pretreated advanced non-small-cell lung cancer: IDEAL 1 and 2. Proc Am Assoc Cancer Res 44, (2nd edn): 1362 (abstract LB-170)

Bianco R, Shin I, Ritter CA, Yakes FM, Basso A, Rosen N, Tsurutani J, Dennis PA, Mills GB, Arteaga CL (2003) Loss of PTEN/MMAC1/TEP in EGF receptor-expressing tumor cells counteracts the antitumor action of EGFR tyrosine kinase inhibitors. Oncogene 22: 2812-2822

Cantley LC, Neel BG (1999) New insights into tumor suppression: PTEN suppresses tumor formation by restraining the phosphoinositide 3kinase/AKT pathway. Proc Natl Acad Sci USA 96: 4240-4245

\section{ACKNOWLEDGEMENTS}

This study was supported by a grant-in-aid from the Ministry of Education, Science, Sports and Culture of Japan (to AG and SK); and also supported for drug supply by AstraZeneca. IRESSA is a trademark of the AstraZeneca group of companies.

Carpenter G, Cohen S (1990) Epidermal growth factor. J Biol Chem 265: 7709-7712

Cohen S, Ushiro H, Stoscheck C, Chinkers M (1982) A native 170000 epidermal growth factor receptor-kinase complex from shed plasma membrane vesicles. J Biol Chem 257: 1523-1531

Ferry D, Hammond L, Ranson M, Kris MG, Miller V, Murray P, Tullo A, Feyereislova A, Rowinsky E (2000) Intermittent oral ZD1839 $\left(\right.$ Iressa $\left.^{\mathrm{TM}}\right)$, a novel epidermal growth factor receptor tyrosine kinase inhibitor (EGFR-TKI), shows evidence of good tolerability and activity: final results from a Phase I study. Proc Am Soc Clin Oncol 19: 3a (abstract 5E)

Fukuoka M, Yano S, Giaccone G, Tamura T, Nakagawa K, Douillard J-Y, Nishiwaki Y, Vansteenkiste J, Kudoh S, Rischin D, Eek R, Horai T, Noda K, Takata I, Smit E, Averbuch S, Macleod A, Feyereislova A, Dong R-P, Baselga J (2003) Multi-institutional randomized phase II trial of gefitinib for previously treated patients with advanced non-small-cell lung cancer. J Clin Oncol 21: 2237-2246

Gemma A, Hagiwara K, Vincent F, Ke Y, Hancock AR, Nagashima M, Bennett WP, Harris CC (1998) hSmad5 gene, a human hSmad family member: its full length cDNA, genomic structure, promoter region and mutation analysis in human tumors. Oncogene 16: 951-956

Gemma A, Takenaka K, Hosoya Y, Matuda K, Seike M, Kurimoto F, Ono Y, Uematsu K, Takeda Y, Hibino S, Yoshimura A, Shibuya M, Kudoh S (2001) Altered expression of several genes in highly metastatic 
subpopulations of a human pulmonary adenocarcinoma cell line. Eur J Cancer 37: $1554-1561$

Gemma A, Takenoshita S, Hagiwara K, Okamoto A, Spillare EA, McMemamin MG, Hussain SP, Forrester K, Zariwala M, Xiong Y, Harris CC (1996) Molecular analysis of the cyclin-dependent kinase inhibitor genes p15INK4b/MTS2, p16 INK4/MTS1, p18 and p19 in human cancer cell lines. Int J Cancer 68: 605-611

Giaccone G, Herbst RS, Manegold C, Scagliotti G, Rosell R, Miller V, Natale RB, Schiller JH, von Pawel J, Pluzanska A, Gatzemeier U, Grous J, Ochs JS, Averbuch SD, Wolf MK, Rennie P, Fandi A, Johnson DH (2004) Gefitinib in combination with gemcitabine and cisplatin in advanced non-small-cell lung cancer: a phase III trial - INTACT 1. J Clin Oncol 22: $777-784$

Haeder M, Rotsch M, Bepler G, Hennig C, Havemann K, Heimann B, Moelling K (1988) Epidermal growth factor receptor expression in human lung cancer cell lines. Cancer Res 48: 1132-1136

Herbst RS, Giaccone G, Schiller JH, Natale RB, Miller V, Manegold C, Scagliotti G, Rosell R, Oliff I, Reeves JA, Wolf MK, Krebs AD, Averbuch SD, Ochs JS, Grous J, Fandi A, Johnson DH (2004) Gefitinib in combination with paclitaxel and carboplatin in advanced non-small-cell lung cancer: a phase III trial - INTACT 2. J Clin Oncol 22: 785-794

Hosoya Y, Gemma A, Seike M, Kurimoto F, Uematsu K, Hibino S, Yoshimura A, Shibuya M, Kudoh S (1999) Alteration of the PTEN/ MMAC1 gene locus in primary lung cancer with distant metastasis. Lung Cancer 25: 87-93

Kim D, Kim S, Koh H, Yoon SO, Chung AS, Cho KS, Chung J (2001) Akt/ $\mathrm{PKB}$ promotes cancer cell invasion via increased motility and metalloproteinase production. FASEB J 15: 1953 - 1962

Kohno T, Takahashi M, Manda R, Yokota J (1998) Inactivation of the PTEN/MMAC1/TEP1 gene in human lung cancers. Genes Chromosomes Cancer 22: $152-156$

Kris MG, Natale RB, Herbst RS, Lynch Jr TJ, Prager D, Belani CP, Schiller JH, Kelly K, Spiridonidis H, Sandler A, Albain KS, Cella D, Wolf MK, Averbuch SD, Ochs JJ, Kay AC (2003) Efficacy of gefitinib, an inhibitor of the epidermal growth factor receptor tyrosine kinase, in symptomatic patients with non-small cell lung cancer. A randomized trial. JAMA 290: $2149-2158$

Lynch TJ, Bell DW, Sordella R, Gurubhagavatula S, Okimoto RA, Brannigan BW, Harris PL, Haserlat SM, Supko JG, Haluska FG, Louis DN, Christiani DC, Settleman J, Haber DA (2004) Activating mutations in the epidermal growth factor receptor underlying responsiveness of non-small-cell lung cancer to gefitinib. N Engl J Med 350: 2129-2139

Mosmann $\mathrm{T}$ (1983) Rapid colorimetric assay for cellular growth and survival: application to proliferation and cytotoxicity assays. J Immunol Methods 65: $55-63$
Naishiro Y, Yamada T, Takaoka AS, Hayashi R, Hasegawa F, Imai K, Hirohashi S (2001) Restoration of epithelial cell polarity in a colorectal cancer cell line by suppression of $\beta$-catenin/T-cell factor 4 -mediated gene transactivation. Cancer Res 61: $2751-2758$

Olayioye MA, Neve RM, Lane HA, Hynes NE (2000) The ErbB signaling network: receptor heterodimerization in development and cancer. $E M B O$ J 19: $3159-3167$

Ozanne B, Richards CS, Hendler F, Burns D, Gusterson B (1986) Overexpression of the EGF receptor is a hallmark of squamous cell carcinomas. I Pathol 149: 9-14

Paez JG, Jänne PA, Lee JC, Tracy S, Greulich H, Gabriel S, Herman P, Kaye FJ, Lindeman N, Boggon TJ, Naoki K, Sasaki H, Fujii Y, Eck MJ, Sellers WR, Johnson BE, Meyerson M (2004) EGFR mutations in lung cancer: correlation with clinical response to gefitinib therapy. Science 304: 1497 1500

Park BK, Zeng X, Glazer RI (2001) Akt1 induces extracellular matrix invasion and matrix metalloproteinase- 2 activity in mouse mammary epithelial cells. Cancer Res 61: 7647-7653

Ranson M, Hammond LA, Ferry D, Kris M, Tullo A, Murray PI, Miller V, Averbuch S, Ochs J, Morris C, Feyereislova A, Swaisland H, Rowinsky EK (2002) ZD1839, a selective oral epidermal growth factor receptor-tyrosine kinase inhibitor, is well tolerated and active in patients with solid, malignant tumors: results of a phase I trial. J Clin Oncol 20: $2240-2250$

Rusch V, Baselga J, Cordon-Cardo C, Orazem J, Zaman M, Hoda S, McIntosh J, Kurie J, Dmitrovsky E (1993) Differential expression of the epidermal growth factor receptor and its ligands in primary non-small cell lung cancers and adjacent benign lung. Cancer Res 53(Suppl): $2379-2385$

Salomon DS, Brandt R, Ciardiello F, Normanno N (1995) Epidermal growth factor-related peptides and their receptors in human malignancies. Crit Rev Oncol Hematol 19: $183-232$

She QB, Solit D, Basso A, Moasser MM (2003) Resistance to gefitinib in PTEN-null HER-overexpressing tumor cells can be overcome through restoration of PTEN function or pharmacologic modulation of constitutive phosphatidylinositol $3^{\prime}$-kinase/Akt pathway signaling. Clin Cancer Res 9: $4340-4346$

Simpson L, Parsons R (2001) PTEN: life as a tumor suppressor. Exp Cell Res 264: $29-41$

Takenaka K, Shibuya M, Takeda Y, Hibino S, Gemma A, Ono Y, Kudoh S (2000) Altered expression and function of $\beta 1$ integrins in a highly metastatic human lung adenocarcinoma cell line. Int J Oncol 17: $1187-$ 1194

Vivanco I, Sawyers CL (2002) The phosphatidylinositol 3-kinase AKT pathway in human cancer. Nat Rev Cancer 2: 489-501 